http://dx.doi.org/10.18232/alhe.916

Artículos

\title{
El debate de la política económica cardenista: una perspectiva contemporánea
}

\section{The Debate on the Economic Policy of the Cardenism: A Contemporary Perspective}

\author{
Sergio Martín ${ }^{1, *}$ (D) 0000-0002-5877-4880 \\ ${ }^{1}$ Sergio Martín y Asociados, Consultoría Macroeconómica, Zacatecas, México. \\ * Correspondencia: sergiomartin007@gmail.com
}

Resumen. La hipótesis que denominaremos tradicional caracterizó a la política económica cardenista como populista, lo cual implicó políticas fiscal y monetaria expansivas. Estas, a su vez, produjeron inflación, sobrevaluación del tipo de cambio y afectación de los balances externos. Posteriormente, la hipótesis que llamaremos alternativa refutó dicha caracterización. El objetivo de este estudio es ofrecer una perspectiva contemporánea de este debate y reivindicar a la hipótesis tradicional con una argumentación mejor sustentada y más acabada, desde el punto de vista metodológico y empírico.

Palabras clave: política económica; política fiscal; política monetaria; populismo; inflación; desequilibrios macroeconómicos.

Abstract. We name a traditional hypothesis that which has established that the economic policy of the Cardenas regime must be defined as populist, which implies the use of expansionary fiscal and monetary policies. These had an impact in rising inflation, overvaluation of the exchange rate and external balances disequilibria. An alternative hypothesis came next, which criticized the traditional one in its own terms. The purpose of this essay is to offer a contemporary view of that debate and to vindicate the traditional hypothesis with improved arguments from a methodological and empirical perspective.

CÓMO CITAR: Martín, S. (2019). El debate de la política económica cardenista: una perspectiva contemporánea. America Latina en la Historia Económica, 26(1), e916. DOI: 10.18232/alhe.916 
economic policy; fiscal policy; monetary policy; populism; inflation; macroeconomic disequilibria.

JEL: N0; E5; E6; H5.

Recibido: 16 de agosto de 2017.

Aceptado: 30 de octubre de 2017.

Publicado en línea: 14 de junio de 2018

Agradecimientos: A los comentarios y sugerencias de Fidel Aroche, Ívico Ahumada, René Borrego, Fernando Chávez, Salvador de Lara, Marco Espinosa, Daniel Garcés, Fausto Hernández y Alejandro Villagómez. Asimismo, deseo destacar que las observaciones realizadas por los evaluadores anónimos contribuyeron a mejorar la versión original del artículo.

\section{INTRODUCGIÓN}

A pesar de las décadas transcurridas no ha sido fácil caracterizar a la política económica cardenista. En efecto, se ha presentado una polémica al respecto entre las hipótesis que denominaremos tradicional y alternativa. La primera predominó al menos por cinco décadas, no sin ser debatida en varios momentos; la segunda, emergió ya estructurada hace cerca de tres décadas. En el centro del debate sobre la política económica cardenista se encuentran, desde nuestra perspectiva, problemas de enfoque, metodológicos y de información estadística.

El objetivo de este estudio es ofrecer una perspectiva contemporánea de este debate y plantear una caracterización de la política económica cardenista más convincente que, en esencia, reivindica a la hipótesis tradicional. La metodología se fundamenta en una línea argumentativa de política económica y evidencia empírica constituida por estadísticas del periodo, así como la introducción de conceptos analíticos relevantes.

La metodología consiste en plantear los términos del debate de las hipótesis que se confrontan, tradicional, alternativa y la perspectiva contemporánea; términos que se cubrirán en la primera sección. A continuación, en la segunda sección presentamos un tema clave del estudio que es la caracterización de populista atribuida al régimen cardenista y la consecuente intencionalidad en su derivación en la política económica. El análisis y tratamiento empírico de la política económica en sus vertientes fiscal y monetaria las exponemos en las secciones tres y cuatro, respectivamente. Los aspectos de política económica anticíclica para hacer frente a la crisis de 1938 aludidos por la hipótesis alternativa y la correspondiente refutación por la perspectiva contemporánea los incluimos en la quinta sección. Por último, reseñamos las conclusiones sobre los argumentos y las evidencias presentadas.

\section{Planteamiento de los téRminos del debate}

El objetivo de esta sección es apuntar de manera sucinta los planteamientos de la hipótesis tradicional y la alternativa, así como aquellos que propone la perspectiva contemporánea sobre la política económica del periodo 1934-1940. 


\section{Hipótesis tradicional}

Esta hipótesis acerca de la política económica del periodo 1934-1940 fue sustentada en uno o varios aspectos de la misma por Pani (1941), Palacios (1953), Ortiz (1942), Martínez (1946), Urquidi (1951), Siegel (1960), Brothers y Solís (1967), Solís (1970), Cavazos (1976), Medina (1978), Cárdenas (1982 y 1987) 1 Bazdresch y Levy (1992) y Turrent (2015), entre otros estudiosos del tema. Los planteamientos son los siguientes:

La política económica de la administración del presidente Cárdenas fue populista en términos económicos $2^{2}$ Lo que implicó que la política fiscal expansiva incurrió en importantes déficit para llevar a cabo el gasto que implicaba el ambicioso programa social y económico cardenista, y que la política monetaria expansiva se materializó a través del financiamiento primario del banco central al gobierno federal y a los bancos nacionales y comerciales. Este proceso generó incrementos sustanciales en la oferta de dinero que al impulsar la demanda agregada y enfrentar una oferta inelástica provocaron alta inflación (véase gráfica 1).

Las consecuencias de este proceso fueron la aplicación de un impuesto inflacionario a la población: 3 sobrevaluación del tipo de cambio ante una inflación internacional baja y un régimen cambiario de tipo de cambio fijo; incremento de importaciones; fuga de divisas; pérdida de reservas internacionales $\mathrm{y}$, finalmente, devaluación cambiaria.

\section{Hipótesis alternativa}

Esta hipótesis fue propuesta por Cárdenas (1992, 1993, 1994b, 2008 y 2015) y adoptada por Suárez (1977, 2005 y 2006), Moreno-Brid y Ros (2010) y Tello (2014). Esta visión alternativa plantea que la política económica de la administración del presidente Cárdenas no fue populista, pues respetó las restricciones macroeconómicas. Esto implicó que la política fiscal expansiva se expresó a través de déficit pequeños, y que la política monetaria expansiva fue relativamente moderada con el propósito de monetizar a la economía conforme esta crecía. Sin embargo, la autoridad monetaria redujo esta expansión cuando detectó el impacto inflacionario de la misma. Asimismo, se plantea que la política económica, fiscal, monetaria y cambiaria adoptó una postura anticíclica exitosa en la crisis de 1938.

\footnotetext{
${ }^{1}$ Cárdenas (2008, p. 816) refiere que él siguió la que aquí llamamos hipótesis tradicional en su tesis doctoral (Cárdenas, 1982 y 1987); sin embargo, posteriormente, revisa su posición para proponer la que denominamos hipótesis alternativa, la cual detallamos en el texto de este estudio.

${ }^{2}$ Véase, en particular, Bazdresch y Levy (1992).

${ }^{3}$ En la administración cardenista se otorga un incremento al salario mínimo real de $7.2 \%$ en 1936, pero en 1937 este se deteriora $15.6 \%$ y tiene una mejora de $4.9 \%$ en 1938. A partir de entonces se mantiene prácticamente constante en términos reales por el resto del sexenio. Sin embargo, si utilizamos para deflactar el índice del costo de la alimentación, en lugar del de precios al mayoreo, calculamos que la capacidad de compra del salario mínimo se deterioró 30 \% cuando la inflación estaba en su punto máximo (véase cuadro 1).
} 
GRÁFICA 1. INFLACIÓN, 1934-1940

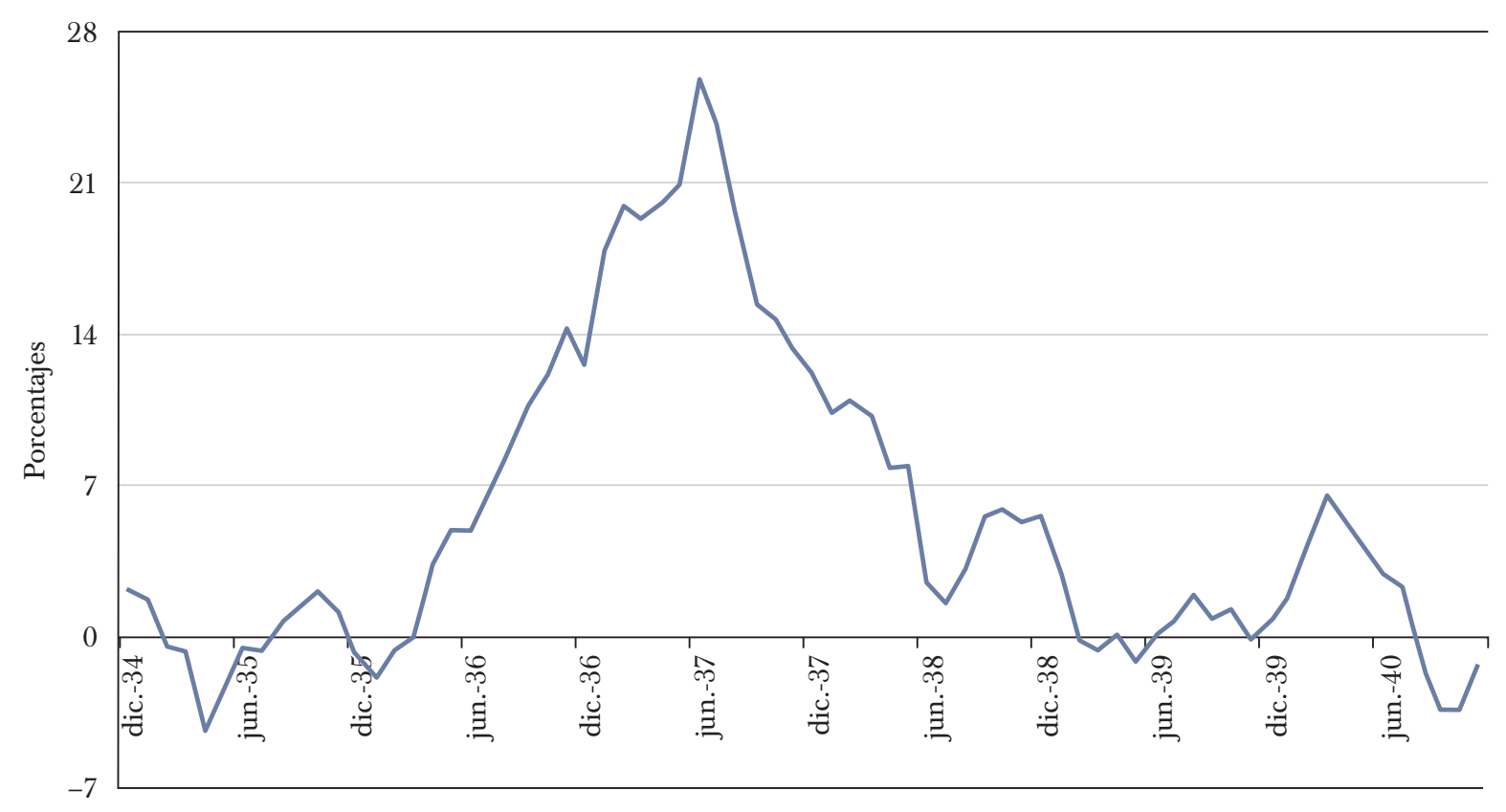

Fuentes: Banco de México (1933-1952).

\section{Perspectiva contemporánea}

Esta perspectiva tercia en el debate con argumentos que refutan la hipótesis alternativa al argumentar que la política económica de la administración del presidente Cárdenas fue populista, pues estableció como máxima prioridad la ejecución de su programa social y económico para alcanzar el crecimiento económico, y al mismo tiempo, menospreció los equilibrios macroeconómicos fundamentales 4

Asimismo, la perspectiva contemporánea señala que de las políticas económicas para enfrentar la crisis en 1938 sólo la monetaria fue consistente al ampliar el crédito. En efecto, la política fiscal fue procíclica y la cambiaria no fue una muestra de flexibilidad o de una decisión de política, sino forzada por las circunstancias y el contexto de incertidumbre política y social.

En suma, la perspectiva contemporánea coincide en lo esencial con la tradicional. Sin embargo, reconocemos que la hipótesis tradicional no ofreció evidencia de la magnitud de los que llamó importantes déficits fiscales y que el análisis del crecimiento de la oferta de dinero es insuficiente para mostrar que hubo un exceso de la misma $5^{5}$ Las objeciones de la hipótesis alternativa a la tradicional parecen, a primera vista, como correctas al mostrar como evidencia déficits fiscales pequeños y una expansión monetaria aparentemente consistente con el crecimiento de la economía. La perspectiva contemporánea provee mejor evidencia empírica para remediar el fallo de la hipótesis tradicional, además de construir una línea argumentativa más sólida para refutar las objeciones de la hipótesis alternativa.

\footnotetext{
${ }^{4}$ Por equilibrios macroeconómicos fundamentales nos referimos a los balances de las finanzas públicas y de la balanza de pagos, así como a la estabilidad monetaria.

${ }^{5}$ Véase, por ejemplo, Cavazos (1976, pp. 76-84).
} 


\section{PopUlisMo ECONÓMICO}

El objetivo de esta sección es presentar las objeciones a la posición de la hipótesis alternativa sobre la caracterización de la política económica cardenista como no populista. Para ello, la versión contemporánea sustentará con base en una definición de populismo económico y fuera de prejuicios político-ideológicos la identificación de la política económica cardenista como populista.

La principal objeción respecto a la hipótesis alternativa es que al caracterizar erróneamente a la política económica cardenista como no populista pierde de vista la intencionalidad y el comportamiento típico de estos regímenes, como lo es la política de arranque y freno. ${ }^{6}$

En efecto, la política económica, fiscal y monetaria, fue expansiva en general, pero en dos fases distintas. Después de un despegue lento en 19357 la política económica tuvo un arranque acelerado en 1936 y un freno relativo al empezar la segunda mitad de 1937. El banco central señala:

el año se inició con un aumento sensible y sostenido de los depósitos bancarios, que principalmente debe atribuirse a los crecidos gastos y fuertes inversiones que, para dar cumplimiento a su programa de obras públicas y reformas sociales, hubo de hacer el gobierno. Con tal motivo, los bancos ampliaron sus operaciones y como consecuencia del origen de que procedieron los depósitos, estos carecieron de estabilidad, y los préstamos bancarios entonces se multiplican sobre bases indeseables. De ahí que la impresión de holgura financiera, que tanto impulso dio a los negocios en los primeros seis meses del año, fuera reemplazada pronto por una situación inversa, cuando la fuga u ocultación de los capitales determinó, a partir de julio, la baja acelerada de los depósitos, obligando a los bancos a activar sus cobros y restringir la concesión de nuevos créditos severamente (Banco de México, 1933-1952, particularmente 1957, p. 10).

En efecto, este arranque constituyó un significativo impulso fiscal del gobierno federal. Aclaremos que el impulso fiscal es el cambio, positivo o negativo, de la posición fiscal, la cual se define como la diferencia entre el balance fiscal observado y el balance fiscal neutro o estructural. En el balance fiscal neutro suponemos, por un lado, una elasticidad unitaria del gasto con el PIB potencial, lo cual sugiere que dicho gasto no presionará a la economía; por otro lado, el ingreso en el balance neutro es consistente con el ingreso fiscal observado en un año base, el cual se elige por su estabilidad. Al balance neutro le restamos el observado y obtenemos la posición fiscal; la cual al restarse de la posición registrada el año anterior da como resultado el impulso fiscal ${ }^{8}$

\footnotetext{
${ }^{6} \mathrm{El}$ concepto de arranque-freno (stop-go) indica el uso de políticas deliberadas de expansión de la demanda agregada que provocan inflación y desequilibrios económicos, los cuales tratan de remediarse, en mayor o menor grado, con políticas contraaccionistas. Cabe aclarar que estas políticas no son exclusivas de los regímenes populistas, pero son generalmente un ingrediente de los mismos.

${ }^{7}$ En 1934-1935, hubo un limitado margen de maniobra gubernamental para impulsar el programa social y económico del régimen debido a que, como en todo inicio de administración, toma un tiempo implantar el programa deseado; asimismo, fue necesaria la resolución del conflicto político con el ex presidente Calles. En este contexto observamos superávits fiscales, estabilidad monetaria, un buen comportamiento de las cuentas externas y la continuación de la recuperación económica posterior a la Gran Depresión (véanse cuadros 1 y 2).

${ }^{8}$ Nótese que el impulso fiscal ofrece resultados que se derivan fácilmente de algoritmos transparentes. Usemos como ejemplo el año 1936, cuando el impulso fiscal fue el más importante. El año anterior hubo un superávit de $0.9 \%$ del PIB y un déficit de 1.3 \% del PIB en 1936; así pues, de una situación en que se sustrajo gasto en 1935 se pasa a otra en la cual
} 
CUADRO 1. INDICADORES ECONÓMICOS, 1934-1940

\begin{tabular}{lccccccc}
\hline & 1934 & 1935 & 1936 & 1937 & 1938 & 1939 & 1940 \\
\hline PIB real per cápita (TA) & 4.9 & 5.6 & 6.1 & 1.6 & -0.1 & 3.6 & -0.3 \\
PIB real (TA) & 6.7 & 7.4 & 8 & 3.3 & 1.6 & 5.4 & 1.4 \\
PIB potencial (TA) & 2.4 & 2.8 & 3.2 & 3.6 & 3.9 & 4.3 & 4.5 \\
PIB nominal (TA) & 9.8 & 9.4 & 17.7 & 27.2 & 7.1 & 6.9 & 6 \\
Deflactor del PIB (TA) & 2.8 & 1.8 & 9 & 23.1 & 5.4 & 1.5 & 4.5 \\
Inflación promedio & 5.5 & -0.3 & 6.3 & 18.4 & 6.3 & 0.5 & 1.5 \\
Inflación fin & 2.2 & -1.1 & 12.5 & 12.1 & 5.7 & 0.6 & 0.8 \\
Tipo de cambio promedio (PPD) & 3.60 & 3.60 & 3.60 & 3.60 & 4.52 & 5.19 & 5.40 \\
Devaluación promedio & 2.9 & 0 & 0 & 0 & 25.6 & 14.8 & 4 \\
Indice de sobrevaluación promedio & 104.6 & 108 & 103.1 & 89.6 & 102.8 & 117.4 & 121.2 \\
Salario mínimo real índice (1934=100) & 100 & 100.3 & 107.5 & 90.8 & 95.2 & 94.7 & 97.1 \\
Salario mínimo real (TA) & $\mathrm{s} . \mathrm{d}$. & 0.3 & 7.2 & -15.6 & 4.9 & -0.5 & 2.5 \\
Balanza comercial en (MD) & 86.1 & 95.5 & 86.3 & 77.3 & 76.1 & 35.2 & 27.4 \\
Balanza comercial (porcentaje del PIB) & 7.5 & 7.6 & 5.8 & 4.1 & 4.7 & 3.6 & 3.5 \\
Exportaciones de bienes (TA) & 71.5 & 16.4 & 3.3 & 15.2 & -25.2 & -11.9 & -2.2 \\
Importaciones de bienes (TA) & 33.1 & 21.6 & 14.3 & 32.4 & -35.9 & 17.3 & 3.3 \\
Reservas internacionales (MD) & 52.9 & 93.2 & 89 & 55.4 & 43.2 & 41.4 & 63.4 \\
Reservas internacionales (porcentaje del PIB) & 4.6 & 7.4 & 6 & 2.9 & 2.7 & 2.8 & 4.2 \\
PIB de Estados Unidos (TA) & 10.8 & 8.9 & 12.9 & 5.1 & -3.3 & 8 & 8.8 \\
Inflación de Estados Unidos & 1.5 & 3 & 1.4 & 2.9 & -2.8 & 0 & 0.7 \\
\hline
\end{tabular}

Abreviaturas: $\mathrm{TA}=$ tasa anual; $\mathrm{PPD}=$ pesos por dólar, $\mathrm{y}$ MD = millones de dólares.

Fuentes: elaboración propia con base en INEGI (2015), Federal Reserve Bank of St. Louis (s. a.) y Banco de México (1933-1952).

A este impulso fiscal habría que añadir la expansión monetaria en un contexto de brecha positiva del producte 9 por un crecimiento importante de $8 \%$ del PIB real. A partir del segundo semestre de 1937 y hasta 1940 el impulso fiscal del gobierno federal se redujo relativamente y la expansión monetaria se moderó, en un contexto de brecha negativa del producto por crecimientos moderados del PIB, con excepción de 1939 (véase cuadro 1).

\section{La hipótesis alternativa}

Esta versión plantea que al régimen cardenista se le caracteriza como populista equivocadamente. Cárdenas (2008) plantea que el régimen cardenista ha sido calificado de populista por su clara cercanía e identificación con las clases de bajos ingresos y marginadas, así como por su extenso programa social que se ha percibido como causante de la expansión del gasto público para educación y salud.

el gasto es mayor en 1936. El "impulso" de un año para otro es aproximadamente de $2.1 \%$ del PIB (-2.1 = -1.3-0.9), cifra similar a la calculada como impulso fiscal, con signo cambiado. Esto es así en cualquier año que se elija de la serie presentada (véase cuadro 10).

${ }^{9}$ Definida como la diferencia entre el PIB observado y el PIB potencial.

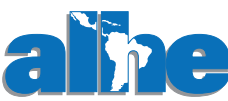


Cárdenas (1992, 1993 y 2008) responde a estos cargos afirmando que la administración cardenista no fue populista, ya que las restricciones macroeconómicas fueron efectivamente consideradas por dicha administración. En efecto, los déficits fiscales fueron pequeños y su financiamiento no fue con créditos significativos del banco central, excepto cuando hubo que enfrentar la crisis de 1938. Si bien el gasto tuvo un alto contenido social, el monto en este rubro casi no creció en el sexenio y la magnitud en que se redujo el gasto militar y administrativo en su momento fue dirigido por igual al gasto económico y social.

\section{La perspectiva contemporánea}

Esta versión introduce como necesaria una definición de populismo económico para tratar con mayor rigor el tema y refutar la hipótesis alternativa ${ }^{10}$ Para mostrar la consistencia de la definición que se adopta y el comportamiento de la administración cardenista haremos uso del axioma jurídico de la admisión de parte. Esto con motivo de que el secretario Suárez no tuvo dificultad alguna para ejercitar y defender abiertamente los principios del significativo gasto público para alcanzar el progreso económico. Igualmente, describiremos los resultados económicos que la política de arranque acelerado en 1936 tuvo en la estabilidad monetaria y desequilibrios externos. Los aspectos de la política fiscal del régimen cardenista los abordaremos en la siguiente sección.

De esta forma, retomamos la definición que Dornbusch y Edwards (1992) ofrecen: "el populismo económico es un enfoque de la economía que destaca el crecimiento y la redistribución del ingreso y menosprecia los riesgos de la inflación y el financiamiento deficitario, las restricciones externas y la reacción de los agentes económicos ante las políticas agresivas ajenas al mercado” (p. 17).

El secretario de Hacienda Eduardo Suárez fue un funcionario de gran experiencia con la difícil encomienda de hacer compatible las exigencias del ambicioso programa social y económico del gobierno cardenista con la estabilidad monetaria. Sin embargo, esto no era posible dada la magnitud de la brecha entre estos dos objetivos ${ }^{11}$ En efecto, hay admisión de parte del propio secretario Suárez en varios puntos al respecto. El primero de ellos nos ubica en el terreno de la polémica sobre cuál es el problema de México y por tanto de la política económica a seguir. Según el secretario de Hacienda, hay dos tendencias antagónicas, una que lo define como el progreso económico y otra que lo plantea como la estabilidad monetaria: "No, señor ingeniero [Pani], el problema de México no está en lograr la estabilidad monetaria. El problema de México en el terreno económico consiste en lograr la elevación del ingreso nacional y la elevación de la renta per cápita, alcanzándose, hasta donde eso es posible, una mejor distribución de dicho ingreso" (Suárez, 1977, p. XCII).

\footnotetext{
${ }^{10}$ Dada la relativa ambigüedad del concepto populismo y su frecuente uso en estudios sobre distintos países y en diferentes contextos políticos, es necesaria una definición puntual que pueda ser contrastada con los argumentos que conforman la evidencia. Asimismo, es condición que esta definición no se haya elaborado específicamente para el caso mexicano, con el fin de evitar un argumento circular al plantear el acomodo de este último con el concepto.

${ }^{11}$ Águila (2010) señala sobre Suárez: "Entre los nuevos tecnócratas [...] destaca el secretario de Hacienda [quien] abrazó desde muy temprano la política de intervencionismo estatal para paliar los efectos más devastadores de la crisis [de 1929] y más adelante también pudo atisbar en la inminente conflagración mundial de 1939 una coyuntura apropiada para aumentar el ahorro de divisas, impulsar la construcción de infraestructura de comunicaciones y pactar en condiciones excepcionales la reanudación del financiamiento externo en México” (p. 94).
} 
El segundo punto está representado por el menosprecio de los riesgos de la inflación $\sqrt{12}$ El secretario Suárez lo muestra cuando declara que concediéndole toda su importancia a la estabilidad monetaria, plantea que hay objetivos más importantes de alcanzar y que es necesario sacrificarla cuando se convierte en un obstáculo:

dos han sido las tendencias antagónicas que presidieron la política financiera en el periodo azaroso que transcurre entre las dos guerras. Por una parte, la política que considera esencial la estabilidad monetaria, principalmente la exterior, y la necesidad de alcanzarla a cualquier precio. La segunda es aquella que, concediéndole toda su importancia a la estabilidad monetaria, estima que puede haber objetivos más importantes que hay que alcanzar y que hay que sacrificarla cuando llega a constituir un obstáculo para alcanzar tales objetivos (Suárez, 1977, pp. XCII-XCIII).

Asimismo, en otro momento, el secretario Suárez (Torres, 1979, p. 288) reitera el punto: "Si por falta [...] de ahorro, aparece el desempleo y los recursos naturales no pueden ser explotados, es legítimo y conveniente crear dinero por medio de la prensa de imprimir, aún a riesgo de alterar el nivel de precios."

El tercer punto está expresado en el menosprecio de los riesgos del financiamiento deficitario. El secretario Suárez lo muestra cuando piensa (1977, p. XcVII) que este financiamiento "era en todo caso un mal necesario que había que minimizar".

Para mostrar el menosprecio de la administración cardenista a los riesgos de las restricciones externas recurriremos al análisis de los resultados económicos en la etapa de arranque, específicamente en el periodo 1936-1937. El deterioro del sector externo se produce especialmente en ese lapso, cuando hubo una pérdida de $3.4 \%$ del PIB en la balanza comercial; en contraste, el deterioro fue de $1.4 \%$ del PIB en la misma balanza en 1938-1940. Las reservas internacionales, también como proporción del PIB, cayeron 4.5 puntos porcentuales, de $7.4 \%$ en 1935 a $2.9 \%$ en 1937; en comparación, las reservas se recuperaron 1.3 puntos porcentuales del PIB en 1938-1940 (véase cuadro 1).

Para mostrar el menosprecio de la administración cardenista a la reacción de los agentes económicos ante las políticas agresivas ajenas al mercado enumeraremos unos ejemplos al respecto. Se tiene la tolerancia del régimen cardenista al incremento de los movimientos de huelga, especialmente en 1935 y 1936, las cuales provocaron alarma en el sector patronal por su combatividad:13 las expropiaciones realizadas, como las de ferrocarriles en 1937, y el uso de una retórica con un fuerte tono antiempresarial y socialista. Sobre este último punto, es necesario destacar que la retórica cardenista tuvo dos fases: una en la que la retórica fue antiempresarial antes de 1938, y posteriormente, otra más moderada. Esto corresponde también a la hipótesis de que en el régimen cardenista fue uno antes de la expropiación de la industria petrolera y otro posteriormente. Por ejemplo, Águila (2010) refiere cómo Cárdenas se dio "a la tarea de una actividad febril de

\footnotetext{
${ }^{12}$ La inflación está calculada con el índice de precios al mayoreo en la Ciudad de México y es consistente con otras mediciones de precios como el deflactor del PIB a nivel promedio anual. El inicio del incremento notable en precios es en abril de 1936, el cual ubica su pico en junio de 1937 con $25.9 \%$ de inflación anual, cuando empieza su declinación hasta alcanzar un retorno a una inflación baja en febrero de 1939.

${ }^{13}$ Medina (1978, p. 20) apunta: "sobra decir que el número de huelgas durante el sexenio cardenista alcanzó un número sin precedentes hasta entonces”. En efecto, según la información que cita este autor, pasaron de 200 en 1934 a 675 en 1936 y disminuyeron gradualmente hasta 325 en 1940. También añade: "más importante que el número de huelgas fue [el aumento] en el número de contratos colectivos de 435 en 1934 a 4321 en 1940”.
} 
reformas económicas e institucionales profundas en el breve lapso de unos tres años y comienza a declinar a partir de su clímax asociado a la expropiación petrolera de marzo de 1938 hasta la controvertida elección de 1940" (p. 97).

\section{POLÍTICA FISCAL}

El objetivo de esta sección es presentar las objeciones a la posición de la hipótesis alternativa respecto a la política fiscal. La principal de ellas es que el planteamiento de moderación fiscal con déficits pequeños del gobierno federal, ofrece una evidencia parcial de la magnitud del déficit fiscal y de los momentos de su impacto macro. Dado el entrelazamiento de la política fiscal y monetaria, lo referente a la banca naciona ${ }^{14}$ lo cubriremos en la siguiente sección, donde el análisis de la política monetaria nos dará una mejor perspectiva del impulso extraordinario que el sector público implicó para la economía.

\section{Hipótesis alternativa}

Sobre la expansión de la política fiscal, Cárdenas (1993) señala que hubo un superávit menor en 1935 de $0.3 \%$ del PIB y déficits pequeños en 1936, 1937, 1939 y 1940 , en promedio de $0.3 \%$ del PIB; el déficit un poco mayor fue de $0.9 \%$ del PIB en 1938, lo cual lo explica como parte de la política anticíclica requerida por las circunstancias ${ }^{15}$ De esta manera, concluye Cárdenas (1993, p.693), esta evidencia contrasta "con la creencia generalizada de que Lázaro Cárdenas fue un presidente que ejerció fuertes déficit fiscales” (véase cuadro 2).

\section{Perspectiva contemporánea}

La versión contemporánea apunta a tres aspectos que permiten tener una lectura distinta de la disciplina fiscal del gobierno federal a la de la hipótesis alternativa.

El primero de ellos es que las cifras históricas del déficit público bajo el enfoque de ingresogasto tienen fallas metodológicas que llevan a problemas de interpretación y, por ello, el enfoque de medición del déficit público mediante el financiamiento del mismo es una mejor práctica. 16 En efecto, las estadísticas proporcionadas por el INEGI (2015) y utilizadas generalmente por los

\footnotetext{
${ }^{14}$ La banca nacional, el equivalente de la banca de desarrollo actual, estaba compuesta por varias instituciones (en paréntesis el año de fundación): Banco Nacional de Crédito Agrícola (1926), Banco Nacional Hipotecario y de Obras Públicas (1933), Nacional Financiera (1934), Banco Nacional de Crédito Ejidal (1935) y Banco Nacional de Comercio Exterior (1937). De todas ellas, la que cobró mayor relevancia en el sexenio cardenista por los recursos a su disposición fue el Banco Nacional de Crédito Ejidal, el cual era la principal institución de fomento a los ejidatarios.

${ }^{15}$ Cabe aclarar que en el sexenio cardenista se inician los déficits recurrentes. En efecto, los registros disponibles del balance del gobierno federal los proporciona el INEGI (2015) con la metodología ingreso-gasto. Estos registros muestran que el presidente Calles mantuvo un superávit en promedio de $0.3 \%$ del PIB en 1924-1928 y sólo incurrió en déficit de 0.1 \% del PIB en 1927. Las administraciones de los presidentes Emilio Portes Gil, Pascual Ortiz Rubio y Abelardo L. Rodríguez mantuvieron un superávit promedio de igual magnitud en 1928-1934. Sólo se presentó un déficit de $0.6 \%$ del PIB en 1933, cuando se impulsó fiscal y monetariamente la recuperación económica de la crisis provocada por la Gran Depresión. En suma, la trayectoria fiscal en la década anterior al cardenismo fue de balances fiscales mayormente superavitarios. Esto se dio así por la falta de financiamiento y una política económica ortodoxa en 1924-1932.

${ }^{16}$ Banco de México (1933-1952, particularmente 1952) en su nota metodológica indica: "La estimación del superávit o déficit del gobierno federal se ha elaborado siguiendo el método del Banco de México, S. A. [...] el cual se apoya en las variaciones de las deudas y de las disponibilidades" (p. 56).
} 
CUADRO 2. BALANCE DEL GOBIERNO FEDERAL (MILLONES DE PESOS)

\begin{tabular}{ccccccc}
\hline Año & $\begin{array}{c}\text { Santillán } \\
\text { y Rosas }\end{array}$ & $\begin{array}{c}\text { Porcentaje } \\
\text { del PIB }\end{array}$ & $\begin{array}{c}\text { Cárdenas } \\
\text { e INEGI }\end{array}$ & $\begin{array}{c}\text { Porcentaje } \\
\text { del PIB }\end{array}$ & $\begin{array}{c}\text { Banco } \\
\text { de México }\end{array}$ & $\begin{array}{c}\text { Porcentaje } \\
\text { del PIB }\end{array}$ \\
\hline 1934 & s. d. & s. d. & 30 & 0.7 & 28.4 & 0.7 \\
1935 & 12.2 & 0.3 & 12 & 0.3 & 42.2 & 0.9 \\
1936 & -22.4 & -0.4 & -21 & -0.4 & -72 & -1.3 \\
1937 & -31.1 & -0.5 & -28 & -0.4 & -69 & -1 \\
1938 & -68.5 & -0.9 & -66 & -0.9 & -17.3 & -0.2 \\
1939 & -20.9 & -0.3 & -5 & -0.1 & -42 & -0.5 \\
1940 & -47.6 & -0.6 & -33 & -0.4 & -72 & -0.9 \\
\hline
\end{tabular}

Nota: los balances fiscales de Santillán y Rosas (1962), Cárdenas (1993) e INEGi (2015) son estimados con la metodología ingreso-gasto; los del Banco de México (1933-1952, particularmente 1951) son estimados con la metodología de financiamiento. 1951).

Fuentes: Santillán y Rosas (1962), INEGI (2015), Cárdenas (1993) y Banco de México (1933-1952, particularmente

analistas no son precisas respecto a los ingresos y gastos fiscales. Por el lado de los ingresos no es claro si incluyen o no los financiamientos y los subsidios virtuales concedidos, y por el lado de los gastos si incluyen o no las amortizaciones y los subsidios virtuales.

La medición del Banco de México (1933-1952, particularmente 1951) reporta el déficit promedio anual de $0.8 \%$ del PIB, el doble del reportado por el INEGI (2015). Sin embargo, más que la magnitud, lo destacable es la configuración del arranque de la política económica cardenista. Los años de mayor déficit fueron 1936 y 1937 con 1.3 y $1 \%$ del PIB, respectivamente ${ }^{17}$ Asimismo, que el impulso fiscal importante de $2.6 \%$ del PIB fue en 1936. Nuestros cálculos del PIB potencial 18 sugieren que la economía podía crecer sin presionar a la oferta en poco más de $3 \%$ y en contraste creció $8 \%$ en $1 9 3 6 \longdiv { 1 9 }$ Posteriormente, los déficit se reducen reflejando el freno relativo que hemos aludido (véanse cuadros 1 y 2 ).

El segundo punto es que, para valorar la disciplina fiscal cardenista, las proporciones del déficit público respecto al PIB, pueden ser complementadas con la correspondencia entre déficit a ingresos. En efecto, escalar variables económicas en relación con el PIB nos permite evaluar su relevancia en términos del tamaño de la economía y el posible impacto en ella, lo que es, obviamente, útil. Sin embargo, en este caso, además del posible impacto en la economía, lo que interesa apreciar es

\footnotetext{
${ }^{17}$ Como referencia registramos que el gasto fue de $6,8.5,7.4,6.3,6.9$ y $7.1 \%$ del PIB en $1935,1936,1937,1938$, 1939 y 1940, respectivamente. Estos resultados son consistentes con los años de mayor déficit: 1936 y 1937.

${ }^{18}$ El cálculo del PIB potencial se realizó con la técnica convencional del filtro de Hodrick-Prescott, el cual es un método para extraer el componente de tendencia de una serie temporal. Dado que este filtro puede presentar cierta imprecisión en los extremos de las series es conveniente realizar una corrección estadística y de ser posible ampliar el periodo de estimación para evitarla en el tramo de interés. En este caso, el periodo de estimación fue de 1925 a 1960.

${ }^{19}$ Puede parecer que el PIB potencial pudiera haber sido mayor en 1936, dado que la tasa de crecimiento promedio fue de $8.5 \%$ en 1933-1935; sin embargo, habría que recordar que el PIB real venía de una caída promedio anual de $4.3 \%$ de 1927 a 1932. Así pues, el crecimiento observado con tasas altas de 1933 a 1935 fue sólo para recuperar el monto del PIB observado en 1926; en otras palabras, la capacidad productiva no aumentó en esa década. De haber habido capacidad instalada para seguir creciendo al $8 \%$ de 1936 en adelante, no se hubiera visto presionada la oferta agregada y los precios, como sucedió en 1936-1937. El mismo cálculo del pIB potencial muestra que este fue aumentando hasta alcanzar alrededor de $6 \%$ en 1950 y de $6.5 \%$ en 1960 .
} 
CUADRO 3. BALANCE E INGRESOS DEL GOBIERNO FEDERAL (MILLONES DE PESOS)

\begin{tabular}{cccccc}
\hline Año & $\begin{array}{l}\text { Banco } \\
\text { de México }\end{array}$ & $\begin{array}{l}\text { Porcentaje } \\
\text { del PIB }\end{array}$ & $\begin{array}{l}\text { Ingresos } \\
\text { efectivos }\end{array}$ & $\begin{array}{c}\text { Porcentaje } \\
\text { del PIB }\end{array}$ & $\begin{array}{c}\text { Déficit/ingresos } \\
\text { en porcentaje }\end{array}$ \\
\hline 1934 & 28.4 & 0.7 & s. d. & s. d. & s. d. \\
1935 & 42.2 & 0.9 & 313 & 6.9 & 13.5 \\
1936 & -72 & -1.3 & 379.9 & 7.1 & -19 \\
1937 & -69 & -1 & 435.1 & 6.4 & -15.9 \\
1938 & -17.3 & -0.2 & 438.3 & 6 & -3.9 \\
1939 & -42 & -0.5 & 494.9 & 6.4 & -8.5 \\
1940 & -72 & -0.9 & 510 & 6.2 & -14.1 \\
\hline
\end{tabular}

Fuente: Santillán y Rosas (1962) y Banco de México (1933-1952, particularmente 1951).

el grado de disciplina fiscal del régimen cardenista. Con este parámetro observamos desviaciones importantes entre ingresos ordinarios y financiamiento, no sorpresivamente, de manera especial en 1936-1932 (véase cuadro 3).

Por último, que la evaluación de la magnitud del déficit debe también considerar el origen del financiamiento para valorar la disciplina fiscal. En el caso de la administración cardenista dicho origen es emisión primaria, lo que aun en magnitudes moderadas, incorpora vulnerabilidad a las finanzas públicas y a la economía 21

\section{Política MONETARia}

El objetivo de esta sección es presentar las objeciones a la posición de la hipótesis alternativa respecto a la política monetaria. La principal refutación de la perspectiva contemporánea es que el financiamiento a través del redescuento y crédito a la banca nacional y comercial no está registrado por esta hipótesis, ignorando una parte importante de las fuentes de expansión monetaria.

\section{Hipótesis alternativa}

Esta hipótesis plantea que la expansión de la política monetaria fue para lubricar de circulante a la economía ya que la administración hacendaria cardenista tenía la convicción de que era necesario aumentar el nivel de precios y dado que venía de una aguda restricción monetaria aumentó el circulante en la economía. El monto casi constante de la oferta de dinero en porcentaje del PIB durante el sexenio cardenista muestra que el crecimiento de la misma creció a la par que la economía:

\footnotetext{
${ }^{20}$ Aquí es importante anotar que los ingresos del gobierno federal representaban sólo $6.5 \%$ del PIB en promedio durante el sexenio.

${ }^{21}$ La perspectiva de la intencionalidad del régimen como una administración populista sugiere que de haber existido el financiamiento disponible los déficits hubieran sido mayores. Simplemente, el programa social y económico era demasiado ambicioso para los recursos financieros a disposición del gobierno.
} 
los niveles de la oferta monetaria como porcentaje del PIB continuaron aumentando lentamente y llegaron a $12.4 \%$ en 1936, para después descender a $10.7 \%$ en 1938 y recuperarse a $12 \%$ en 1939 [...] En general, la oferta de dinero fluctuó desde los años veinte hasta los treinta entre 10 y $12.5 \%$, con excepción de los peores años de la Gran Depresión. Es decir, no se puede hablar de una gran expansión de la cantidad de dinero en circulación, pues más bien su crecimiento acompañó a la expansión de la economía (Cárdenas, 2008, p. 817).

Prosigue el planteamiento de la hipótesis alternativa al afirmar que cuando la inflación rebasó los límites deseados, las autoridades redujeron la base monetaria para detener la inflación, tal como se observa en la caída de su crecimiento en 1937. Asimismo, que la inflación no sólo fue causada por el banco central, sino también por los bancos comerciales y el público:

en los años de 1934 a 1936 la base monetaria contribuyó con más del 100 \% del crecimiento de la oferta [...]. Naturalmente, eso contribuyó al crecimiento de los precios a partir de mediados de 1936 [...]. Sin embargo, esta tendencia se rompió en 1937 cuando el Banco de México restringió la base monetaria, probablemente cuando se dio cuenta que la inflación se estaba acelerando, pero la oferta de dinero nominal continuó su crecimiento ya que los bancos tenían una fuerte demanda de crédito, por lo que recurrieron a sus reservas para hacer crecer el crédito interno (Cárdenas, 1993, pp. 688-689).

\section{Perspectiva contemporánea}

Esta perspectiva señala que la política monetaria fue expansiva ya que el banco central fungió como un cuasi banco de desarrollo para producir el financiamiento, pero con el agravante de que su fondeo provenía de la emisión primaria.

Asimismo, que la monetización de la economía era ya adecuada para la actividad económica en 1936, y que la restricción de la base monetaria en 1937 fue por la reducción del componente externo de la base, es decir, por la caída de las reservas internacionales debida a la sobrevaluación y otras causas adversas y no por el componente interno, el cual aumentó. Por último, que los bancos comerciales y el público actuaron bajo la premisa de una política económica expansiva al aprovechar la oportunidad de financiamiento disponible y las bajas tasas.

\section{Expansión monetaria}

El análisis de la expansión monetaria se realiza a través de la oferta, base y multiplicador, así como la elasticidad de billetes y monedas y las bajas tasas de interés. Estas variables explican cabalmente la expansión monetaria del periodo. Nuestros cálculos indican que, después de la grave crisis de faltante de circulante en 1931, el proceso de remonetización de la economía se alcanzó aproximadamente en 1934 o 1935 y de ahí en adelante hubo un crecimiento de la oferta de dinero por encima de la actividad económica. Medina (1978) señala que "[e]s muy probable que cuando el gobierno decidió adoptar esta política monetaria [de aumento del circulante] no esperaba que la inflación resultase tan aguda como parecía indicarlo la teoría" (pp. 40-41).

Efectivamente, la oferta de dinero real a fines de 1926 se recuperó en 1934. El monto del PIB real que se tenía en 1926, el año previo al inicio de la Gran Depresión en México (la cual inició prematuramente en 1927 para el país), se recuperó aproximadamente al final de 1935. Ambos 
años, 1926 y 1927, tuvieron inflaciones promedio prácticamente nulas, -1.8 y $-0.3 \%$, respectivamente. En el proceso de recuperación de 1932 a 1935, las tasas medias de crecimiento del PIB real y de la oferta de dinero real fueron de $8.5 \%$ en ambas variables. De esta forma, observamos que hubo un proceso de monetización de la economía desde su punto más bajo en 1932 hasta 1935. En consecuencia, podemos argüir que la monetización de la economía estaba razonablemente empatada entre volumen de la producción y la cantidad de dinero real para adquirirla en 1935 (véase cuadro 4).

Esto fue especialmente cierto en 1936, con una tasa de la oferta monetaria real de $13.6 \%$ y de nuevo en 1939 con una tasa de $18 \%$, los dos años con crecimiento del PIB importante en el sexenio (8 y $5.4 \%$, respectivamente) ${ }^{22}$ Cabe aclarar que la oferta monetaria también se expandió de manera significativa en 1940. Sin embargo, al contrario de años anteriores, en los cuales la tendencia de aumento fue por el componente interno de la base monetaria, el incremento del último año del sexenio se debió principalmente al componente externo de la base (reservas internacionales) por la entrada de capitales, es decir, un choque externo causado por el inicio de la segunda guerra mundial (véanse cuadros 4 y 5 ).

Es un planteamiento debatible la hipótesis alternativa según la cual la gran expansión de la cantidad de dinero en circulación acompañó a la expansión de la economía. Esto es, un porcentaje relativamente estable de la oferta monetaria respecto al PIB lo que indica es que la velocidad del dinero es estable; no que la cantidad de dinero estuvo acorde con el crecimiento de la economía 23 (véase cuadro 6).

El componente interno de la base monetaria creció en función del financiamiento al gobierno y a las bancas nacional y comercial. Esta expansión de la base monetaria se expresó en un multiplicador monetario superior a la unidad. Asimismo, la expansión de la oferta monetaria mediante la base monetaria fue crecientemente explicada por el incremento de billetes y monedas y no por los depósitos en el banco central (véanse cuadros 5 y 6 ).

La restricción de la base monetaria en 1937 se produjo por la reducción del componente externo de la base, es decir, por la caída de las reservas internacionales, no como una decisión de política de contención monetaria. En realidad, como apuntamos en el párrafo anterior, la parte interna de la misma aumentó. La evidencia nos muestra que la base monetaria disminuyó $2 \%$ del PIB, cuando el componente externo se redujo en $3 \%$ del PIB y el interno compensó al crecier $1 \%$ del PIB. Específicamente, el desglose del componente interno muestra que el financiamiento de la banca central a los bancos fue el único elemento que aumentó en $1.4 \%$ del pIB y el correspondiente al gobierno y empresas disminuyó $0.4 \%$ del PIB (véase cuadro 5).

\footnotetext{
${ }^{22} \mathrm{El}$ crecimiento de $7.4 \%$ del PIB real en 1935 fue también muy importante; no obstante, recordemos que el PIB real de ese año todavía se encontraba en la etapa de recuperación a los niveles de una década atrás (véase cuadro 4).

${ }^{23}$ Asimismo, esta relativa estabilidad de la velocidad del dinero sugiere que la variación de precios está asociada a la correspondiente de la oferta monetaria. En este contexto, tanto la hipótesis tradicional como la alternativa han coincidido que el disparador del incremento de precios fue el incremento de la oferta monetaria por el financiamiento primario del Banco Central al gobierno y a la banca, especialmente en 1936.
} 
CUADRO 4. PIB REAL Y OFERTA MONETARIA REAL, MILLONES DE PESOS, 1926-1940 ${ }^{\mathrm{A}}$

\begin{tabular}{ccccc}
\hline Año & PIB real & Tasa anual & $\begin{array}{c}\text { Oferta mo- } \\
\text { netaria real }\end{array}$ & Tasa anual \\
\hline 1926 & 453 & 6 & 445 & 18 \\
1927 & 433 & -4.4 & 425 & -4.5 \\
1928 & 436 & 0.6 & 546 & 28.4 \\
1929 & 419 & -3.9 & 565 & 3.7 \\
1930 & 393 & -6.3 & 576 & 1.9 \\
1931 & 406 & 3.3 & 262 & -54.5 \\
1932 & 345 & -14.9 & 385 & 46.9 \\
1933 & 384 & 11.3 & 419 & 8.8 \\
1934 & 410 & 6.7 & 464 & 10.7 \\
1935 & 441 & 7.4 & 491 & 5.9 \\
1936 & 476 & 8 & 558 & 13.6 \\
1937 & 492 & 3.3 & 480 & -14 \\
1938 & 500 & 1.6 & 505 & 5.2 \\
1939 & 527 & 5.4 & 596 & 18 \\
1940 & 534 & 1.4 & 686 & 15.1 \\
\hline
\end{tabular}

a El PIB y la oferta en términos reales se obtuvieron de las cifras nominales correspondientes y el deflactor del PIB base $2008=100$. Se usa este año base debido a que el artículo es parte de una investigación más amplia que cubre el periodo 1921-2015.

Fuente: INEGi (2015) y Banco de México (1979). 


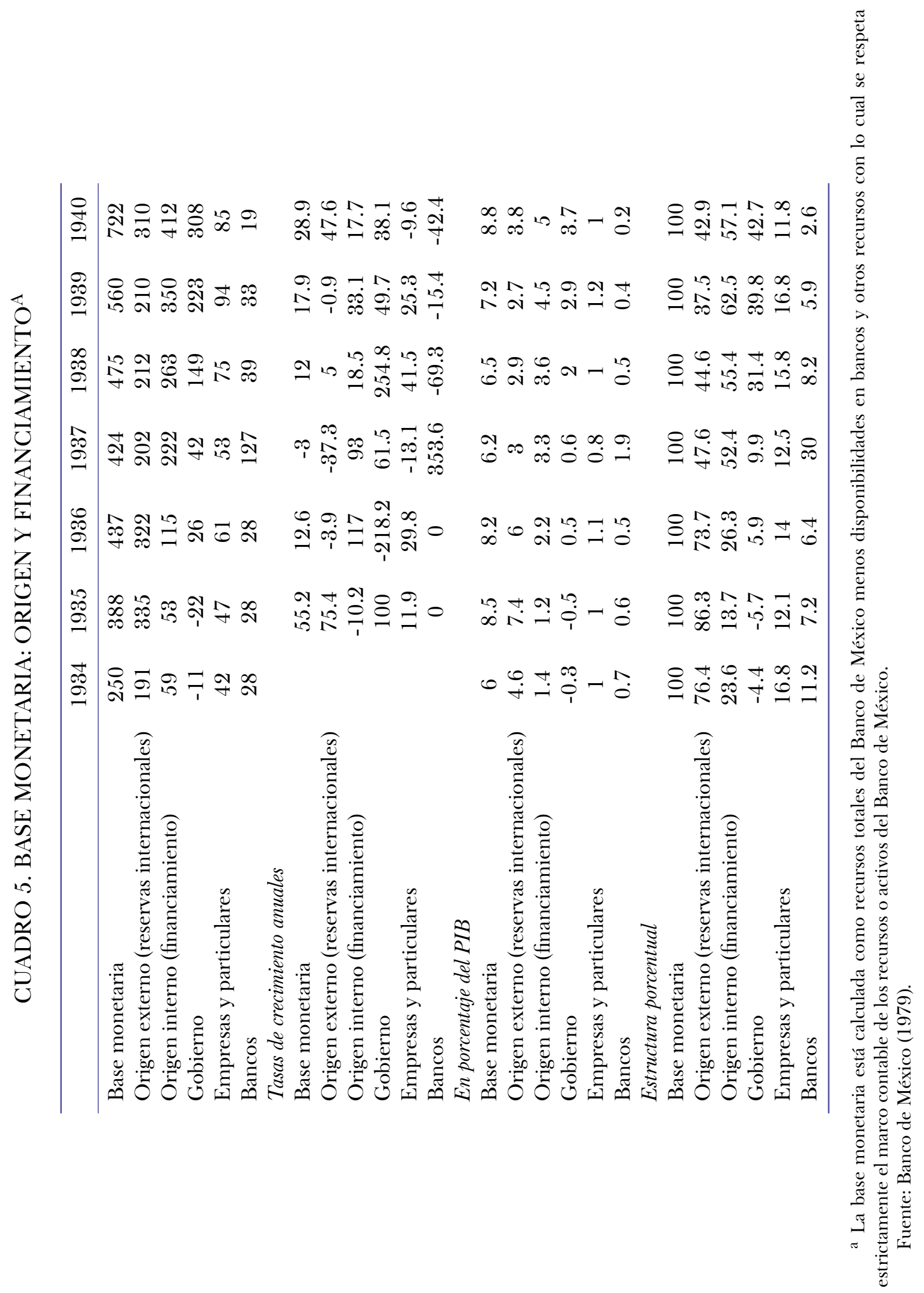


La hipótesis alternativa plantea que, no obstante la restricción de la base monetaria, el crecimiento de la oferta monetaria continuó por el financiamiento de los bancos. Lo que esta hipótesis no menciona es que fue la banca nacional la que hizo preponderadamente este financiamiento. En efecto, el financiamiento de las instituciones financieras permaneció prácticamente constante con $10.3 \%$ del PIB en 1937, respecto a 1936; sin embargo, su composición cambió ${ }^{24}$

En suma, la reducción de la base monetaria no se debió a una política de moderación de las autoridades monetarias, sino a la caída de las reservas internacionales, que las autoridades compensaron parcialmente con mayores recursos a la banca nacional. Esto es, no había intención de frenar el crecimiento de la base; en realidad fueron las condiciones de sobrevaluación, expectativas devaluatorias y el incremento de importaciones las que hicieron caer las reservas internacionales y, por lo tanto, la base monetaria.

Otro elemento a considerar es que, si bien el banco central inició una reducción de los redescuentos a partir del segundo semestre de 1937, esta moderación en la expansión monetaria resultaría frustrada en esencia 25

Igualmente, las tasas de interés no reflejaban el riesgo de los financiamientos en el periodo. De acuerdo con Palacios (1953) las tasas de interés eran menores que el nivel de riesgo que sugerían las condiciones económicas. Esto reflejaba que los bancos asociados se respaldaban en el banco central para ampliar sus operaciones en vez de considerar el riesgo existente y cobrar tasas de interés de acuerdo con ello. Este comportamiento de las bancas nacional y comercial incentivó al público para solicitar mayor crédito.

\section{Financiamiento al gobierno federal}

Entre los puntos más polémicos de la política monetaria está el financiamiento del banco central al gobierno. El primero es el aumento del saldo deudor del gobierno que alcanzó 308000000 cuando al inicio del sexenio había un ahorro neto (véanse cuadros 5 y 7). Asimismo, hubo límites legales que se violaron en el procedimiento, como el sobregiro de finales de 1937. Este último, como se comentó más arriba, fue utilizado para financiar las actividades del Banco Ejidal, lo cual ilustra dos aspectos de la política monetaria: primero, que se estaba abusando de la práctica de redescuento con lo que se incurría en un alto riesgo de impago y, segundo, que para evitarse fue sustituido por crédito directo al gobierno. Suárez (1977) explica el origen del sobregiro: "el Banco de México se negaba a redescontar los documentos que le enviaban los bancos agrícolas, principalmente el Ejidal, alegando que no llenaban los requisitos [y dada la necesidad de financiamiento se] propuso [...] que con ese suplemento yo ampliase las operaciones del Banco Ejidal” (pp. 112-113).

\footnotetext{
${ }^{24}$ En efecto, el banco central y la banca comercial perdieron 0.2 y $1 \%$ del PIB, respectivamente, en participación. En consecuencia, fue la banca nacional la que aumentó su participación en ese porcentaje, $1.2 \%$ del PIB. El fondeo de la banca nacional provenía fundamentalmente del banco central y al final de 1937 del gobierno, con el crédito del sobregiro (véase cuadro 9).

${ }^{25}$ Efectivamente, la disminución realizada más que se compensó con el llamado sobregiro de 89300000 de pesos, el cual otorgó como crédito al gobierno federal para remediar la negación de redescuentos al Banco Ejidal. Justamente, el saldo de redescuentos de 49500000 de pesos en diciembre de 1936 paso a 15100000 de pesos en diciembre de 1937, una reducción de 34400000 de pesos o poco menos de la mitad del sobregiro (véase cuadro 9).
} 


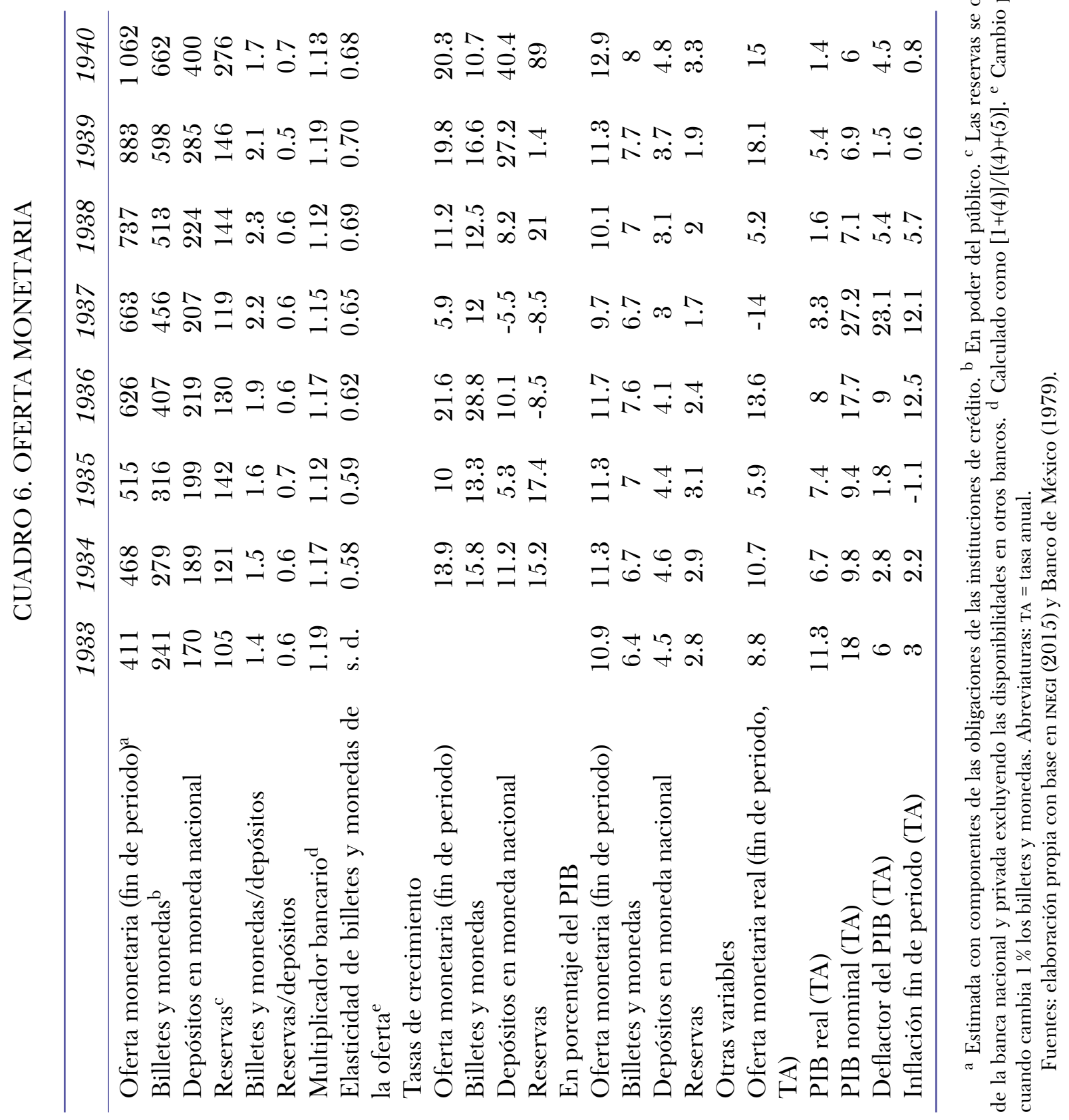




\section{CUADRO 7. FINANCIAMIENTO AL GOBIERNO FEDERAL, 1934-1940 (EN MILLONES DE PESOS}

\begin{tabular}{lccccccc}
\hline Financiamiento & 1934 & 1935 & 1936 & 1937 & 1938 & 1939 & 1940 \\
\hline Cuenta del gobierno federal (2+3-6) & - & - & 21.8 & 122.7 & 146.9 & 223 & 249.9 \\
Bonos de caminos & - & 4.2 & 6.8 & 16.5 & 28.7 & 39.3 & 42.2 \\
Crédito & - & - & 15 & 106.2 & 118.2 & 183.7 & - \\
Límite legal & - & 14.7 & 21.7 & 33.1 & - & - & - \\
Sobregiro (1-4) & - & - & 0.1 & 89.6 & - & - & - \\
Revalorización reserva & - & - & 0 & 0 & 33.2 & - & - \\
Financiamiento al gobierno federal & -11 & -22 & 26 & 42 & 149 & 223 & 308 \\
Valores & 2 & 5 & 15 & 17 & 31 & 102 & 296 \\
Crédito & -13 & -27 & 11 & 25 & 118 & 121 & 12 \\
\hline
\end{tabular}

a Si se incluye la revalorización de la reserva internacional a la cuenta del gobierno el saldo al final del sexenio ascendería a 33200000 pesos más.

Fuente: Banco de México (1979).

El segundo punto es que hubo modificaciones a la Ley Orgánica del Banco de México para normar y legalizar operaciones que no estaban permitidas en 1936, y para 1938 se volvieron a realizar modificaciones que flexibilizaron el financiamiento primario al gobierno ${ }^{26}$ Un punto a destacar aquí es la manipulación de las cuentas banco central-gobierno en la reestructuración del saldo deudor de este último. Esto se hizo a través de la emisión de un bono a 50 años, plazo que se firma en noviembre de 1940, esto es, al fin del sexenio cardenista.

El último punto se refiere a que la revalorización contable de las reservas internacionales por la devaluación, en 1938, veló el grado de endeudamiento gubernamental. Esto es, las reservas internacionales al ser valuadas en pesos en el balance del banco central a un tipo de cambio mayor, incrementaron la magnitud de los activos, lo que representó un excedente contable que se compensó como reducción de deuda del gobierno federal al banco central en 1938 27

Financiamiento al sector privado

El financiamiento al sector privado por el banco central que se denomina redescuento es un aspecto de gran importancia ${ }^{28}$ Este medio de financiamiento fue un instrumento para la expansión crediticia que apoyó la actividad económica (véase cuadro 8). 29

Anaya (2011) el investigador que realizó un análisis cuidadoso de varios aspectos relacionados con este tipo de crédito apunta:

\footnotetext{
${ }^{26}$ En la nueva Ley Orgánica del Banco de México de 1936 la principal modificación en este sentido fue el monto de la línea de crédito, la cual se amplió de 5 a $10 \%$ del promedio de los ingresos fiscales de los tres años anteriores.

${ }^{27}$ Esta maniobra constituye el primer caso en la historia de la economía mexicana de los remanentes del banco central que se entregan al gobierno federal.

${ }^{28}$ Anaya (2011) define a la operación de redescuento como "una vía para conceder crédito a los bancos asociados del mismo modo que lo pueden ser la concesión de cualquier tipo de préstamo” (p. 77).

${ }^{29}$ Anaya (2011) apunta: "el sector más beneficiado [fue] el agroindustrial y, en especial, los productores de azúcar, henequén, algodón” (p. 84).
} 
GUADRO 8. REDESGUENTOS Y CRÉDITO BANCARIO, 1932-1940 (MILLONES DE PESOS)

\begin{tabular}{lccccccccc}
\hline Mes & 1932 & 1933 & 1934 & 1935 & 1936 & 1937 & 1938 & 1939 & 1940 \\
\hline Enero & 1.5 & 25.8 & 26.5 & 35.2 & 41.4 & 46.9 & 16.4 & 56.3 & 90.2 \\
Febrero & 3.1 & 26 & 28.5 & 33.5 & 44 & 49.1 & 19.2 & 57.5 & 104.9 \\
Marzo & 6.7 & 27.9 & 31.3 & 37 & 46.4 & 48.2 & 32.3 & 57.3 & 93.7 \\
Abril & 11.2 & 25.3 & 30.1 & 41 & 50.7 & 52.9 & 36.8 & 52.5 & 83.3 \\
Mayo & 14.6 & 24.8 & 31.9 & 42.8 & 56.9 & 57.7 & 41 & 62.4 & 78.3 \\
Junio & 15.9 & 24.1 & 33.8 & 43.6 & 60.7 & 50.2 & 48.2 & 63.2 & 76.2 \\
Julio & 16.8 & 23.9 & 32.9 & 45.6 & 60.8 & 46.4 & 50 & 71.5 & 71.2 \\
Agosto & 18.2 & 25.3 & 31.3 & 44.4 & 60.3 & 43.4 & 47.9 & 79.7 & 73.1 \\
Septiembre & 17.3 & 28.5 & 31.3 & 40.7 & 55.2 & 36.6 & 46.2 & 78.5 & 81.4 \\
Octubre & 16.2 & 29.5 & 33.3 & 39.1 & 50.8 & 28.5 & 46.1 & 74.8 & 78.2 \\
Noviembre & 16.2 & 28 & 34.8 & 37.9 & 56.1 & 13.8 & 53.8 & 65.4 & 74.5 \\
Diciembre & 23 & 25 & 34.2 & 41 & 49.5 & 15.1 & 61 & 77.5 & 62 \\
Promedio & 13.4 & 26.2 & 31.7 & 40.1 & 52.7 & 40.7 & 41.6 & 66.4 & 80.6 \\
Crédito bancarioa & 310 & 334 & 341 & 374 & 547 & 698 & 772 & 1021 & 1106 \\
Tasa anual & - & 7.7 & 2.1 & 9.7 & 46.3 & 27.6 & 10.6 & 32.3 & 8.3 \\
\hline
\end{tabular}

a Crédito bancario estimado para 1932.

Fuente: Banco de México (1933-1952) en Anaya (2011, p. 81).

en el curso de 1935 Banxico observó con inquietud que el impulso dado al redescuento era aprovechado por los bancos para no arriesgar sus propios capitales de trabajo. Al analizar estos comportamientos e inquieto por la ampliación de la oferta de dinero posiblemente mal respaldada, el Consejo de Administración inició una revisión de la política del redescuento [... ] que daría lugar a una Ley Orgánica [en agosto de 1936] y a seguir una política de mayor prudencia (p. 87).

En relación con los cambios a la política de redescuentos en la nueva Ley Orgánica del banco central en 1936 el mismo autor señala:

los cambios mayores fueron de orden administrativo e implicaron revisar mejor los documentos que serían considerados viables para ser redescontados con el objeto de asegurar bien las garantías de las líneas de crédito. Esta nueva política trajo una consecuencia previsible: frenar el crecimiento de los documentos redescontados [asimismo, se dieron rumores de que el] Banco de México eludía operaciones para favorecer compromisos con el gobierno (Anaya, 2011, p. 89).

Anaya (2011) también comenta la manera en que algunos juzgaron el impacto de este cambio institucional sobre el redescuento en 1937: "se señalaría como una causa de la contracción que resintió la actividad económica en 1937 [...]. En realidad, el Banco de México sólo reaccionó a los abusos de la banca y a la necesidad de encontrar mejores garantías de propiedad con objeto de controlar posibles crecimientos de riesgo" (p. 95). 
La hipótesis alternativa, en este contexto, probablemente aduciría que la reducción de los redescuentos obedeció al motivo de desacelerar la oferta monetaria y frenar la inflación por la autoridad monetaria. Aquí reiteramos lo que apuntamos más arriba, de que cuando la política de redescuento se hace restrictiva hacia fines de 1937 se sustituye con crédito directo del banco central al gobierno, por lo que la contención monetaria es inexistente.

\section{Financiamiento a empresas}

El financiamiento del banco central y de la banca nacional tuvo una dinámica intensa con el fin de apoyar el programa social y económico gubernamental debido a que no tomaba en cuenta el riesgo crediticio. Por otra parte, el financiamiento de la banca comercial creció a un ritmo menor debido al ambiente de volatilidad financiera; un ejemplo son las reducciones de su crédito en 1937 y 1938. Efectivamente, las tasas medias de crecimiento anual del crédito del banco central, la banca nacional y la banca comercial fueron de 52.7, 31.8 y $9 \%$, respectivamente. Por ello, el banco central y la banca nacional ganaron participación en el financiamiento total como porcentaje del PIB; esto es, el crecimiento del financiamiento en el sexenio de alrededor de cinco puntos porcentuales respecto al PIB, fue producto exclusivo de la actividad del banco central y de la banca nacional (véase cuadro 9).

\section{Política ANTicíclica}

El objetivo de esta sección es presentar las objeciones a la posición de la hipótesis alternativa respecto a la política económica que se implantó para enfrentar la crisis de 1938. La principal refutación de la perspectiva contemporánea es que la política fiscal fue procíclica y para la cambiaria no había otra opción que la de devaluar por las circunstancias adversas del momento ${ }^{30}$ Sólo la política monetaria reaccionó al incrementar el crédito y mantener su nivel en proporción del PIB.

\section{Política fiscal}

La hipótesis alternativa señala que la política fiscal consistió en ejercer un déficit que constituyera un estímulo, pero que no fuera demasiado importante para evitar presiones inflacionarias, por ello, se registró el déficit de $0.9 \%$ del PIB.

La perspectiva contemporánea refuta lo anterior al plantear que la política económica fiscal fue, en realidad, procíclica. Las cifras históricas del déficit público bajo el enfoque de ingreso-gasto señalan, como se mencionó, un mayor gasto fiscal para enfrentar la crisis de 1938; sin embargo, el enfoque alternativo de medición por el financiamiento indica un déficit fiscal menor en comparación con 1936-1937 de sólo 0.2 \% del PIB. Nuestra lectura es que la moderación fiscal se debió a la decisión de evitar una mayor agravación de la crisis, en un contexto impactado por las circunstancias del choque externo de la crisis estadunidense, las turbulencias de la expropiación de la

\footnotetext{
${ }^{30} \mathrm{La}$ administración cardenista generó niveles altos de incertidumbre. En lo económico, la determinación principal era el nivel alto de sobrevaluación y la crisis estadunidense de 1937-1938; en lo político, la decisión de la expropiación de la industria petrolera y la sucesión presidencial, la cual fue una causa importante de nerviosismo y expectativas negativas. Véase Medina (1978).
} 


\section{GUADRO 9. FINANCIAMIENTO DE LAS INSTITUCIONES DE CRÉDITO A GOBIERNO Y EMPRESAS (EN MILLONES DE PESOS)}

\begin{tabular}{|c|c|c|c|c|c|c|c|}
\hline & 1934 & 1935 & 1936 & 1937 & 1938 & 1939 & 1940 \\
\hline \multicolumn{8}{|c|}{ Financiamiento a gobierno y empresas } \\
\hline Banco central & 31 & 25 & 87 & 95 & 224 & 317 & 393 \\
\hline Banca nacional & 54 & 66 & 130 & 246 & 238 & 293 & 283 \\
\hline Banca comercial & 256 & 283 & 330 & 357 & 310 & 411 & 430 \\
\hline Instituciones de crédito & 341 & 374 & 547 & 698 & 772 & 1021 & 1106 \\
\hline \multicolumn{8}{|c|}{ Tasas de crecimiento anuales y medias } \\
\hline Banco central & & -19.4 & 248 & 9.2 & 135.8 & 41.5 & 24 \\
\hline Banca nacional & & 22.2 & 97 & 89.2 & -3.3 & 23.1 & -3.4 \\
\hline Banca comercial & & 10.5 & 16.6 & 8.2 & -13.2 & 32.6 & 4.6 \\
\hline Instituciones de crédito & & 9.7 & 46.3 & 27.6 & 10.6 & 32.3 & 8.3 \\
\hline \multicolumn{8}{|c|}{ En porcentaje del PIB } \\
\hline Banco central & 0.7 & 0.6 & 1.6 & 1.4 & 3.1 & 4.1 & 4.8 \\
\hline Banca nacional & 1.3 & 1.5 & 2.4 & 3.6 & 3.3 & 3.8 & 3.4 \\
\hline Banca comercial & 6.2 & 6.2 & 6.2 & 5.2 & 4.3 & 5.3 & 5.2 \\
\hline Instituciones de crédito & 8.2 & 8.2 & 10.2 & 10.3 & 10.6 & 13.1 & 13.4 \\
\hline \multicolumn{8}{|c|}{ Estructura porcentual } \\
\hline Banco central & 9.1 & 6.7 & 15.9 & 13.6 & 29 & 31 & 35.5 \\
\hline Banca nacional & 15.8 & 17.6 & 23.8 & 35.2 & 30.8 & 28.7 & 25.6 \\
\hline Banca comercial & 75.1 & 75.7 & 60.3 & 51.1 & 40.2 & 40.3 & 38.9 \\
\hline Instituciones de crédito & 100 & 100 & 100 & 100 & 100 & 100 & 100 \\
\hline
\end{tabular}

Fuente: Banco de México (1979).

industria petrolera, la devaluación cambiaria y las restricciones de financiamiento no inflacionario. En consecuencia, el impulso fiscal para ese año fue negativo en $0.9 \%$ del PIB, lo que, en realidad, implicó un retiro del apoyo fiscal a la actividad económice 31 (véase cuadro 10).

El impacto de la recesión estadunidense de mayo de 1937 a junio de 1938 en la economía mexicana fue mitigado tanto por la corta duración de dicha recesión, trece meses, como por la tendencia de impulso de la política económica que se implementaba en la economía mexicana. No obstante, un factor en contra fue la expropiación de la industria petrolera y sus consecuencias

\footnotetext{
${ }^{31}$ Cárdenas (1993) señala “[...] la expansión fiscal del gobierno [...] puede caracterizarse como no deseada o accidental, pues, en realidad, su intención no era realizar amplios déficits fiscales para contrarrestar la recesión económica, como queda de manifiesto en la reducción del gasto público en el segundo semestre de 1938, cuando el gobierno advirtió que sus ingresos fiscales no estaban aumentando como lo habían hecho en los dos años anteriores. Más bien, el gobierno estaba plenamente consciente de que excesos en el gasto público muy por encima de sus ingresos no eran benéficos para la economía” (p. 695).
} 
GUADRO 10. IMPULSO FISGAL DEL GOBIERNO FEDERAL

\begin{tabular}{ccccc}
\hline & Balance fiscal (1) & Balance neutro (2) & $\begin{array}{c}\text { Posición fiscal } \\
(3)=(2)-(1)\end{array}$ & $\begin{array}{c}\text { Impulso fiscal } \\
(4)=(3) t-(3) t-1\end{array}$ \\
\hline 1934 & 0.7 & -0.6 & -1.2 & s. d. \\
1935 & 0.9 & -0.3 & -1.2 & 0 \\
1936 & -1.3 & 0 & 1.3 & 2.6 \\
1937 & -1 & 0 & 1 & -0.3 \\
1938 & -0.2 & -0.2 & 0.1 & -0.9 \\
1939 & -0.5 & -0.1 & 0.4 & 0.4 \\
1940 & -0.9 & -0.3 & 0.6 & 0.1 \\
\hline
\end{tabular}

Fuente: elaboración propia con base en Banco de México (1933-1952, particularmente 1951).

en exportaciones ${ }^{32}$ Estos resultados nos sugieren que si bien la crisis en Estados Unidos de 19371938 tuvo un impacto negativo en las cuentas externas mexicanas el choque en el sector externo se localiza fundamentalmente a partir de 1938 y no en 1937. En efecto, las exportaciones crecieron en 1937 y cayeron en 1938; por su parte, el volumen de la producción industrial trimestral, publicado por el Banco de México (1933-1941) mantuvo su crecimiento hasta el cuarto trimestre de 1937.

\section{Política monetaria}

La hipótesis alternativa señala que la política monetaria impidió reducciones excesivas del crédito, y, por último, que la política cambiaria fue flexible, en comparación con el inicio de la década, y se tomó la decisión de devaluar y dejar flotar el tipo de cambio.

En la perspectiva contemporánea se estima que la reacción monetaria anticíclica fue reiniciar la práctica de los redescuentos. La oferta monetaria aumentó ligeramente en 1938, después de haberse debilitado en 1937. En particular, se presentó un incremento del financiamiento de las instituciones crediticias a las empresas ${ }^{33}$ y lo más importante, se dio este impulso crediticio a través de los redescuentos a partir de marzo de 1938, los cuales habían declinado drásticamente desde mediados de 1937 (véanse cuadros 8 y 9). Igualmente, desde esta perspectiva la devaluación del tipo de cambio era impostergable y no fue una señal de flexibilidad en la política anticíclica. ${ }^{34}$ En

\footnotetext{
${ }^{32}$ Las exportaciones de minerales industriales, oro, plata, y petróleo crudo y derivados, se redujeron en $36.4 \%$ en 1938 con respecto a 1937 . Estas exportaciones representaban poco más del 70 \% del total. La caída total de las exportaciones fue de $25.2 \%$ (véase cuadro 1 ).

${ }^{33}$ Este punto se comentó más arriba al indicar que fue el banco central el que aumentó notablemente el crédito de 1.4 a $3.1 \%$ del PIB en 1938. De hecho, la banca nacional disminuyó ligeramente el financiamiento en $0.3 \%$ del PIB y la comercial lo hizo en un punto porcentual del PIB respecto al año anterior (véanse cuadros 5 y 10).

${ }^{34}$ Cárdenas (1993, p. 687) menciona esta flexibilidad en comparación con la ortodoxia que se observó en la Gran Depresión. Sin embargo, pensamos que es impropio calificarla así ya que la política económica cardenista era claramente no ortodoxa y que tratar de mantener el tipo de cambio hubiera implicado tener una política monetaria altamente restrictiva, cuestión difícil de imaginar de la política económica cardenista.
} 
marzo de 1938, tanto por la sobrevaluación de $27.2 \%$ como por las represalias internacionales que se pensaba podrían materializarse, la devaluación era obligada a riesgo de agotar las reservas en unos pocos meses más.

\section{Conclusiones}

La perspectiva contemporánea, al igual que la hipótesis tradicional, caracteriza a la política económica del régimen cardenista como populista, lo que implica que careció de disciplina fiscal y monetaria. En este marco se presentó un comportamiento de arranque y freno, igualmente propio de las políticas económicas expansivas populistas.

La hipótesis alternativa al no reconocer esta caracterización populista evalúa incorrectamente la intencionalidad del arranque acelerado en 1936-1937, con su impacto en la estabilidad monetaria y los desequilibrios macroeconómicos provocados. Al mismo tiempo, interpreta erróneamente el freno relativo posterior en 1938-1940 como un manejo prudente de la política económica cardenista y no como un débil esfuerzo del banco central de poner orden y reducir el riesgo en la expansión monetaria; asimismo, las circunstancias adversas del periodo contribuyeron a la desaceleración de la oferta monetaria.

La hipótesis alternativa sostiene que la política fiscal expansiva fue moderada, pero el problema de las estadísticas del déficit público, ya comentado, la lleva a una medición errónea de la magnitud del mismo y de los momentos en que se produjo. Asimismo, no toma en cuenta el impulso fiscal, así como el contexto de la brecha del producto. Por ello, no es precisa su interpretación de la postura fiscal en el auge (1936-1937) y en la etapa de desaceleración posterior (1938-1940).

La hipótesis alternativa sostiene que la política monetaria fue moderada al plantear que el crecimiento de la oferta monetaria fue para remonetizar la economía. Esto se refuta al mostrar que el nivel de monetización de la economía era ya adecuado en 1936 y que la estabilidad de la proporción de la oferta respecto al PIB no prueba que crecía conforme lo demandaba la economía; el crecimiento de la oferta monetaria fue mayor que el crecimiento del PIB de 1936 en adelante. Igualmente, la hipótesis alternativa omite incorporar al análisis el financiamiento de la banca nacional y el banco central al sector privado, lo cual impide evaluar el apoyo cuasi fiscal y su impacto en la economía.

La hipótesis alternativa plantea que la política fiscal y monetaria fue expansiva y que la política cambiaria fue flexible para adoptar una postura anticíclica en 1938. En la parte fiscal dicho impulso no existió y, de hecho, el comportamiento fue procíclico; no obstante, en la monetaria si hubo un esfuerzo de mantener el nivel de crédito al sector privado y al gobierno. Por último, la política cambiaria no fue flexible como decisión de política y la devaluación se debió a las circunstancias económicas y políticas del momento, las cuales también determinaron el posterior periodo de flotación.

Lo que destaca de esta síntesis argumental es que la implantación acelerada del programa social y económico cardenista de 1936 y la primera mitad de 1937 y su impacto en la inflación y los desequilibrios macroeconómicos llevan a la devaluación de 1938. Posteriormente, se presenta un

\footnotetext{
${ }^{35} \mathrm{La}$ cifra se obtuvo con los cálculos usuales para el tipo de cambio real con base en el diferencial de inflaciones México-Estados Unidos y el tipo de cambio. El cálculo de Cárdenas (2008, p. 823) es más bajo: 21.9 por ciento.
} 
relativo freno o moderación del impulso gubernamental principalmente por la vía fiscal y menos por la monetaria que, junto con el choque favorable del inicio de la segunda guerra mundial, hace viable cierta estabilidad económica en el resto del sexenio cardenista.

\section{LISTA DE REFERENCIAS}

Águila, M. T. (2010). Raíz y huella económicas del cardenismo en el cardenismo, 1932-1940. México: Fondo de Cultura Económica.

Anaya, L. (2011). El Banco de México y la economía cardenista: economía, cambio institucional y reglas monetarias. México: Universidad Autónoma del Estado de Morales/Miguel Ángel Porrúa.

BAnco de México (1933-1952). Informe anual. México: Autor.

BAnco de México (1979). Moneda y banca: cuaderno 1925-1978. México: Autor.

Bazdresch, C. y Levy, S. (1992). El populismo y la política económica de México, 1970-1982. En R. Dornbusch y S. Edwards (eds.), Macroeconomía del populismo en la América Latina. México: Fondo de Cultura Económica.

Brothers, D. y Solís, L. (1967). Evolución financiera de México. México: Centro de Estudios Monetarios Latinoamericanos.

CÁRdenas, E. (1982). México’s industrialization during the great depression: Public policy and private response (Tesis doctoral). Yale University, New Haven.

Cárdenas, E. (1987). La industrialización mexicana durante la Gran Depresión. México: El Colegio de México.

Cárdenas, E. (1992). Comentarios al artículo de C. Bazdresch y S. Levy. En R. Dornbusch y S. Edwards (eds.), Macroeconomía del populismo en la América Latina. México: Fondo de Cultura Económica.

Cárdenas, E. (1993). La política económica en la época de Cárdenas. El Trimestre Económico, 60(239), 675-697.

CÁrdenas, E. (ed.) (1994a). La gran depresión y la industrialización: el caso de México. En Historia económica de México. México: Fondo de Cultura Económica.

Cárdenas, E. (1994b). La Hacienda pública y la política económica, 1929-1958. México: Fondo de Cultura Económica.

Cárdenas, E. (2008). El mito del gasto público deficitario en México (1934-1956). El Trimestre Económico, 75(4), 809-840.

CÁRdenas, E. (2015). El largo curso de la economía mexicana. De 1790 a nuestros días. México: El Colegio de México/Fondo de Cultura Económica.

Cavazos, M. (1976). Cincuenta años de política monetaria. En E. Fernández (ed.), Cincuenta años de banca central. México: Fondo de Cultura Económica.

Dornbusch, R. y Edwards, S. (eds.) (1992). El populismo y la política económica de México, 19701982. México: Fondo de Cultura Económica.

Federal Reserve Bank of St. Louis (s. a.). FRED Economic Data. Recuperado de https://fred.stlouisfed.org/

Instituto Nacional de Estadística y Geografía (Inegi) (2015). Estadísticas históricas de México 2014. México: Autor.

Martínez, R. (1946). El Banco de México. En H. M. Кock (ed.), Banca central. México: Fondo de Cultura Económica.

Medina, L. (1978). Del cardenismo al avilacamachismo. En Historia de la revolución mexicana, 1940-1952 (Vol. 18). México: El Colegio de México. 
Moreno-Brid, J. C. y Ros, J. (2010). Desarrollo y crecimiento en la economía mexicana: una perspectiva histórica. México: Fondo de Cultura Económica.

Nacional Financiera (1974). La economía mexicana en cifras 1974. México: Autor.

OrTiz, R. (1942). La moneda mexicana, análisis histórico de sus fluctuaciones. Las depreciaciones y sus causas. México: Banco de México.

Palacios, M. (1953). Dos documentos sobre política hacendaria mexicana. Problemas Agrícolas e Industriales de México, 5(1).

Pani, A. (1941). Tres monografías. México: Atlante.

Santillán, R. y Rosas, A. (1962). Teoría general de las finanzas públicas y el caso de México. México: Universidad Autónoma de México.

Siegel, B. (1960). Inflación y desarrollo. México: Centro de Estudios Monetarios Latinoamericanos.

Solís, L. (1970). La realidad económica mexicana, retrovisión y perspectivas. México: Siglo XXI.

Suárez, E. (1977). Comentarios y recuerdos (1926-1946). México: Porrúa.

Suárez, F. (1977). Bosquejo biográfico. En E. Suárez (ed.), Comentarios y recuerdos (1926-1946). México: Porrúa.

SuÁrez, F. (2005). Dos visiones de la política económica de México: un debate en la historia (1946 a 1970). En M. E. Romero (ed.), Historia del pensamiento económico de México, problemas y tendencias (1821-2000). México: Trillas.

SuÁrEz, F. (2006). Desarrollismo y ortodoxia monetaria (1927-1952) el debate entre dos visiones de política financiera mexicana. En M. E. Romero (ed.), Temas a debate, moneda y banca en México, 1884-1954. México: Universidad Autónoma de México.

Tello, C. (2014). La economía política de las finanzas públicas de México 1917-2014. México: Universidad Autónoma de México.

Torres, B. (1979). México en la segunda guerra mundial. En Historia de la revolución mexicana. México: El Colegio de México.

Turrent, E. (2015). Historia del Banco de México, consolidación y formación de la tormenta (vol. II). México: Banco de México.

Urquidi, V. (1951). El papel de la política fiscal y monetaria en el desarrollo económico. El Trimestre Económico, 18(75), 636-653. 